University of California, Hastings College of the Law UC Hastings Scholarship Repository

Faculty Scholarship

2010

\title{
Aligning Ethics with Medical Decision-Making: The Quest for Informed Patient Choice
}

Jaime S. King

UC Hastings College of the Law, kingja@uchastings.edu

Benjamin W. Moulton

Follow this and additional works at: http://repository.uchastings.edu/faculty_scholarship

Part of the Medical Jurisprudence Commons

\section{Recommended Citation}

Jaime S. King and Benjamin W. Moulton, Aligning Ethics with Medical Decision-Making: The Quest for Informed Patient Choice, 38 Journal of Law 85 (2010).

Available at: http://repository.uchastings.edu/faculty_scholarship/325

This Article is brought to you for free and open access by UC Hastings Scholarship Repository. It has been accepted for inclusion in Faculty Scholarship by an authorized administrator of UC Hastings Scholarship Repository. For more information, please contact marcusc@uchastings.edu. 


\title{
UNIVERSITY of CALIFORNIA HASTINGS COLLEGE OF THE LAW
}

\section{Faculty Publications}

UC Hastings College of the Law Library

\author{
Author: Jaime S. King \\ Source: $\quad$ Journal of Law, Medicine \& Ethics \\ Citation: $\quad 38$ J.L. Med. \& EthICs 85 (2010). \\ Title: $\quad$ Aligning Ethics with Medical Decision-Making: The Quest for Informed Patient \\ Choice
}

Originally published in JOURNAL OF LAW, MEDICINE \& ETHICS. This article is reprinted with permission from Journal OF LAW, MEDICINE \& ETHICS and American Society of Law, Medicine \& Ethics. 


\title{
Aligning Ethics with Medical Decision-Making: The Quest for Informed Patient Choice
}

\author{
Benjamin Moulton and Jaime S. King
}

$\mathrm{M}$ edical practice should evolve alongside medical ethics. As our understanding of the ethical implications of physician-patient interactions becomes more nuanced, physicians should integrate those lessons into practice. As early as the 1930s, epidemiological studies began to identify that the rates of medical procedures varied significantly along geographic and socioeconomic lines. ${ }^{1}$ Dr. J. Alison Glover recognized that tonsillectomy rates in school children in certain school districts in England and Wales were in some cases eight times the rates of children in other districts, with the only significant predictive factors being the current chief medical officer in the area and the socioeconomic well-being of the child's parents. ${ }^{2}$ Unfortunately, Dr. Glover's work revealed that the increase in tonsillectomies did not improve the health of adolescent patients and appeared to be performed "as a routine prophylactic ritual for no particular reason and with no particular result."3 These prophylactic surgeries often had severe consequences, as the President of the Royal Society of Medicine noted: "It was sad to reflect that many of the anesthetic deaths mentioned by Dr. Glover were due to the children's having undergone an unnecessary operation." Since the 1970s, research by Jack Wennberg and colleagues has also revealed similar geographic variations in procedure rates for a wide range of medical conditions in the United States. ${ }^{5}$ In accordance with Glover's findings, Wennberg concluded

Benjamin Moulton, J.D., M.P.H., is a Lecturer in Health Lawe at Harvard School of Public Health and a Senior Legal Advisor at the Foundation for Informed Medical Decision Making. From 1994 to 2008 he served as the Executive Director of the American Society of Law, Medicine $ఠ$ Ethics. Jaime S. King, J.D., Ph.D., is an Associate Professor of Law at the University of California, Hastings College of the Lare. that physician recommendations and communication to the patient were major driving forces of these variations, rather than clinical need or patient preference. ${ }^{6}$

As a result, over the last three decades, medical ethicists have shifted from guiding physicians to focus on beneficence and improving patient health as emphasized in the Hippocratic oath ${ }^{7}$ toward a more subjective and "patient-centered" practice, which also prioritizes patient autonomy in medical decision-making. ${ }^{8}$ While this shift toward autonomy is well represented in the literature and ethical guidelines, health services research demonstrates that in clinical practice many physicians have yet to strike the ideal balance between absolute patient autonomy and beneficence. Recent studies have found that most physicians still undervalue disclosure and underestimate the variability in patient preferences. ${ }^{9}$ Alternatively, in an effort to promote a more "patient-centered" model of decisionmaking, we have received anecdotal reports that other physicians have altered their disclosure practices to provide patients with information on the risks and benefits of the treatment options, but then require the patient to make the treatment decision without the benefit of the physician's medical opinion. ${ }^{10}$ In these infrequent instances, the pendulum has swung too far. The unmitigated rise of autonomy can result in the decline of beneficence. ${ }^{11}$ In today's medical practice, patients frequently receive either too little medical information to make an informed treatment decision or too little physician opinion to feel confident in their choice. To satisfy their ethical obligations to patients, health care providers should implement a system of medical decision-making that balances the importance of both ethical principles.

Shared medical decision-making can accomplish this goal by promoting patient autonomy, while also 
leaving room for physician beneficence. In this article, Section I reviews the evolution in the medical literature regarding the relative importance of autonomy and beneficence and argues that a shared decision-making approach can best achieve the desired balance. Section II suggests integrating shared decision-making into medical practice through use of the following: (1) successful practice models; (2) state policy incentives; and (3) national health care legislation.

\section{The Ethical Principles of Medical Decision-Making}

Respect for autonomy and beneficence are two of the fundamental principles that govern medical ethics. ${ }^{12}$ While beneficence obligates physicians to act for the benefit of their patients, ${ }^{13}$ respect for autonomy requires singular goal of improved health. ${ }^{17}$ However, medical care does not occur in a vacuum.

The beneficence-focused, decision-making model compelled patients to adopt not only their physician's treatment choices, but also their physician's values, levels of risk aversion, and personal preferences. ${ }^{18}$ Often treatment decisions impact significantly more than the patient's health, such as their ability to work, care for their children, or participate in their favorite activities. Beneficence unbounded by concerns for patient autonomy quickly turns into paternalism. ${ }^{19}$ In the name of promoting patient health, physicians often independently selected a treatment regiment without providing information to patients regarding available alternatives or the risks associated with a particular treatment. Over time, it became clear that

In this article, Section I reviews the evolution in the medical literature regarding the relative importance of autonomy and beneficence and argues that a shared decision-making approach can best achieve the desired balance. Section II suggests integrating shared decision-making into medical practice through use of the following: (1) successful practice models; (2) state policy incentives; and (3) national health care legislation.

them to ensure that patients have enough information to make a reasoned and autonomous medical decision. ${ }^{14}$ Although these principles can complement one another, they also regularly conflict, requiring their relative priority to be established. Medical ethicists, physicians and patients have repeatedly redefined the relationship of these principles in order to enhance the medical decision-making process. Unfortunately, such revisions have not gained general adherence in practice thereby leaving the balance between the two principles in day-to-day medical care suboptimal at best.

\section{A. Beneficence}

The American College of Physicians requires physicians "to promote good and act in the best interest of the patient and the health of society." ${ }^{15}$ Historically, this duty has been thought of in terms of the patient's medical benefit, rather than promoting her best interests on a broader level..$^{16}$ As a result of their superior training and knowledge of medicine, physicians bore the responsibility of acting as agents for their patients, determining the best treatment options to fulfill the patients often had other goals, preferences, and values that competed with their physician's goal of improved health or their physician's opinion of what they ought to do.

In a liberal society, the beneficence-focused model impinges patients' rights on both a theoretical and an empirical level. 'Theoretically, it frustrates patients' abilities to establish their own conception of the good and to make autonomous choices about how to best obtain those goals. ${ }^{20}$ This frustration would have been less damning if physicians proved to be good agents for their patients' long-term goals. Unfortunately, empirical research demonstrates that physicians are highly inaccurate at predicting the goals and preferences of their patients. ${ }^{21} \mathrm{As}$ a result, paternalism, and in many ways beneficence, have fallen out of favor in medical ethics with the rise of the patients' rights movement and the legal doctrine of informed consent. In the late 20th century, respect for autonomy began to supercede beneficence and paternalism as the leading medical decision-making paradigm due to strong arguments from lawyers, judges, and medical ethicists that patients should determine what happened 
to their bodies, as they ultimately had to experience the consequences of the chosen treatment decision. ${ }^{22}$

\section{B. Autonomy}

Respect for autonomy has become the dominant and controlling principle in both informed consent law and medical ethics. The American Medical Association's Code acknowledges that "[ $t]$ he patient's right of self-decision can be effectively exercised only if the patient possesses enough information to enable an informed choice" and that "the patient should make his or her own determination about treatment."23 The AMA requires physicians to disclose "all relevant medical information to patients" to enable them to make medical decisions based upon their personal beliefs, values, and life goals. Under this standard, physicians must respect patients' decisions even when those decisions do not promote their physical well-being or conform with the physician's medical judgment. ${ }^{24}$ At the extreme, courts have upheld a competent patient's right to decline medical treatment even when that treatment would be life saving. ${ }^{25}$

The importance of this shift has gained both national and international recognition. In 2002, after several years of collaboration, the American Board of Internal Medicine in conjunction with the American College of Physicians and the European Federation of Internal Medicine published a charter on medical professionalism for the new millennium that urged all physicians to follow three fundamental ethical principles and ten attendant professional responsibilities. In pertinent part, the charter notes that " $[\mathrm{p}]$ hysicians must be honest with their patients and empower them to make informed decisions about their treatment.... and ensure that patients are completely and honestly informed before the patient has consented to treatment and after treatment has occurred." ${ }^{26}$ In 2006, a group of large national employers, reached out to the American College of Physicians and the Academy of Family Physicians to create the Patient-Centered Primary Care Collaborative (PCPCC), dedicated to improving physician-patient relations and health care delivery. Now with the support of its ever increasing membership that includes over 300 large national employers, most of the major primary care physicians associations, health care benefits companies, academic medical centers, and health care quality improvement organizations, the PCPCC established joint principles of ethical patient care that require "patients [to] regularly participate in decision-making" and physicians to seek feedback "to ensure that the patients' expectations are being met." ${ }^{27}$ In 2008, the National Quality Forum, a not-for-profit organization created to address national health care quality measurement and reporting, convened the National Priorities Partnership (NPP) to focus on six of the U.S. health care system's top priorities. First on the NPP's list is Patient and Family Engagement, which entails ensuring that (1) physicians ask patients for feedback on their care; (2) patients receive the tools necessary to manage and navigate their care; and (3) patients have access to the information and assistance necessary to make informed treatment choices. ${ }^{28}$ The existence of these national and international bodies demonstrates the growing momentum behind a shift away from the historical roles of the paternalistic physician and the compliant patient to a new model of an autonomous, informed, and participatory patient. ${ }^{29}$

While the medical community has espoused the value of autonomy in principle, much more work must be done to promote patient autonomy in practice. Health services research conducted in the last 15 years reveals a consistent pattern of inadequate information disclosure and low patient comprehension and retention. In a multi-national study conducted in 2004, the Commonwealth Fund found that 31 percent of sicker patients ${ }^{30}$ in the United States left their physician's office without having important questions answered, which was the highest percentage among the five countries studied (Australia, Canada, New Zealand, and the United Kingdom). ${ }^{31}$ Likewise, 47 percent of sicker patients reported that the physician did not ask their ideas and opinions about treatment and care. ${ }^{32}$ This startling data suggests not only a consistent failure to meet the disclosure requirements necessary to obtain a legal consent, but also a breach of fundamental medical ethics on a systemic level.

Variation between the United States and the four other nations studied may have occurred for a number of reasons. Some variation may result from financial incentives within the U.S. health care system, as physicians are generally reimbursed based on the volume of procedures they perform, not time spent discussing the procedures with patients. ${ }^{33}$ Other inadequacies may result from physicians' lack of understanding of patients' informational needs. In a study comparing physicians' and patients' opinions on the importance of different aspects of outpatient care, patients prioritized the factors related to the provision of information second only to clinical skill, while physicians prioritized it sixth out of the nine domains of outpatient practice. ${ }^{34}$ In a study of physician and patient encounters in outpatient care, Braddock et al. found that while physicians disclosed the nature of the patient's condition $83 \%$ of the time, they only discussed the risks of the procedure with the patient in $9 \%$ of all cases and in $22 \%$ of more serious cases, such as an invasive in-office procedure or change in medi- 
cation. ${ }^{35}$ Alternatives to the physician's recommended treatment were discussed even less frequently. In addition to the underprovision of information, Calkins et al. found that physicians tend to overestimate patient comprehension of their discharge instructions. ${ }^{36} \mathrm{~A}$ study conducted at the Mayo clinic found that patients failed to report $54 \%$ of the "most important health problems" discussed by physicians with respect to their medical care when asked to recount the health problems discussed during the encounter. ${ }^{37}$ Despite ethical mandates requiring disclosure of all relevant medical information and legal standards obligating physicians to obtain an informed consent based on those disclosures, clinical evaluation research studies suggest that patients are routinely asked to make decisions about treatment choices in the face of what can only be described as avoidable ignorance.

Decisions made under a shroud of ignorance have negative consequences for both individuals and the U.S. health care system as a whole, in the form of unnecessary procedures. In the absence of complete information, individuals frequently opt for procedures they would not otherwise choose. Mounting clinical evaluative evidence suggests that the number of surgical procedures performed, even when justified by practice guidelines, actually exceeds patients' desires when they are fully informed through a shared decision-making process. ${ }^{38}$ This incongruence occurs most often in cases of preference sensitive care, where for a specific condition the patient faces multiple treatment options with varied risks and benefits. Selecting between preference sensitive treatment options often involves significant tradeoffs that affect the patient's quality or length of life. ${ }^{39}$ To make an informed decision, patients need evidence-based medical information on the risks and benefits of all treatment options. However, they also need proper health provider guidance to make a decision that aligns their personal values and medical goals. Not all clinically appropriate patients will prefer to have surgery over less invasive treatments, if the long-term outcomes are similar or the surgery has significant side effects. For instance, a study of patients who satisfied the clinical guidelines for knee arthroplasty found that when fully informed, no more than $15 \%$ preferred to have the surgery. ${ }^{40}$ Inadequate disclosures can result in costly, unwanted and unnecessary procedures that are often accompanied by significant complications or side effects. On a systemic level, differences in the information disclosed to patients and their level of comprehension can produce significant variations in the rates of preference sensitive treatments options. ${ }^{41}$ Respecting a patient's autonomy requires physicians to provide patients with sufficient information to make an informed decision
Box I

\section{Common Preference Sensitive Conditions}

- Early Stage Prostate Cancer

- Early Stage Breast Cancer

- Osteoarthritis of the Knee

- Osteoarthritis of the Hip

- Osteoarthritis of the Spine

- Chest Pain associated with Coronary Artery Disease

- Stroke Risk associated with Carotid Artery Disease

- Ischemia due to Peripheral Artery Disease

- Gall Stones

- Enlarged Prostate (BPH)

Source: Dartmouth Atlas White Paper 2008

and to ensure their comprehension of the various altenatives, risks, and benefits.

However, the emphasis on patient autonomy in medical decision-making can go too far. ${ }^{42}$ While the medical and ethical literature continues to decry "old paternalism," a number of articles have equally denounced a decision-making model that relies entirely on patient autonomy. Discussed under many names, including the independent choice model, $4: 3$ mandatory autonomy, ${ }^{44}$ the patient-centered model, ${ }^{45}$ and the fact-provider model, ${ }^{46}$ this model requires the physician to provide all of the relevant medical facts and statistics on all treatment options to patients, but then remain neutral regarding the rest of the patient's decision. Rather than making a treatment recommendation, the physician turns over the entire responsibility of making the treatment choice to the patient. While current data are lacking regarding the extent to which physicians use this model in actual practice, anecdotal reports suggest that its use is not entirely theoretical and its frequent discussion in the medical ethics literature warrants its consideration herein. ${ }^{47}$

Making an informed medical choice requires more than medical information. In a study of treatment refusals by oncology patients, Titia van Kleffens and colleagues found that patients perceive medical information and make treatment decisions based on their prior experiences, the experience of others close to them, their ideas, convictions, and values. ${ }^{48}$ While all of these factors are important, engaging in a treatment discussion with a physician can greatly assist patients to identify any biases or misconceptions they have and to better understand their overall decision. Dale Collins and colleagues recently demonstrated that patient decisional conflict scores in women with early-stage invasive breast cancer were significantly reduced both following the use of the decision aid and then again after surgical consultation. ${ }^{49}$ After use of the decision 
aid, patients felt better prepared to engage in a discussion with their physician, as they were more aware of their own priorities and goals. ${ }^{50}$ However, consultation with the physician appeared most effective at reducing patient uncertainty regarding treatment choices. ${ }^{51}$ In making treatment decisions, patients need to have access to three things: (1) access to medical information relevant to them in making the decision; (2) the advice of their treating physician; and (3) the autonomy to make decisions in accordance with their personal values and goals. For instance, only an individual patient can decide whether taking the risk of surgery and a diminished quality of life in the present is worth a decrease in disease risk in the future. However, the individual can only accurately weigh those risks and benefits through a detailed discussion with his or her physician or designated member of the health care team. By isolating patients from physicians and closing down communication, this decisionmaking model leaves patients vulnerable to numerous decision-making biases and effectively cheats them out of an accessible expert opinion.

Autonomy need not come at the expense of beneficence. Demonstrating respect for patient autonomy does not require physicians to remain neutral sources of information in the care of their patients. Health services research conducted in the last ten years has found that the vast majority of patients want to be informed and involved in medical decision-making. ${ }^{52}$ In addition, patients also strongly preferred that the physician's opinion remain an integral part of the treatment decision..$^{53}$ Respecting a patient's autonomy means respecting their wishes regarding what information is relevant to their decision and how much they want to participate in making their treatment decision. ${ }^{54}$

Balancing autonomy and beneficence may result in several different, but equally appropriate outcomes. In rare cases, a competent patient may refuse all relevant information and defer all decision-making authority to the physician. The decision to not receive information is a valid expression of her autonomy. Tom Beauchamp and James Childress argue that " $[\mathrm{t}]$ here is a fundamental obligation to ensure that patients have the right to choose, as well as the right to accept or decline information. Forced information, forced choice, and evasive disclosure are inconsistent with this obligation. ${ }^{55}$ In the majority of cases in which physicians provide information to patients, four possible outcomes exist. First, the physician and the patient arrive at a mutual treatment decision. Second, the patient selects a treatment option that the physician does not prefer, but will provide. Third, the physician and patient do not agree and the patient seeks care elsewhere, or fourth, the patient can defer the treat- ment choice to the physician. A physician's ethical obligation with respect to treatment decision-making should be to assist patients to select both a decisionmaking pathway and a treatment option that best satisfies their personal and medical goals.

We now have the opportunity to strike a better balance between autonomy and beneficence. Rather than selecting one principle to the exclusion of the other, shared decision-making (SDM) offers a model for medical decision-making that balances the importance of both patient autonomy and physician beneficence.

\section{Striking a Balance: Shared Decision-Making}

In developing new standards of behavior, establishing uniformity of terminology is essential. The concept of shared decision-making varies in name, definition, and connotation significantly within the academic literature. For instance, its features have been referred to as informed decision-making, informed shared decision-making, partnership, patient involvement, patient-centered care, and evidence-based patient choice. ${ }^{56}$ Likewise, the term shared decision-making has been used to mean many different things, such as a process requiring mutual agreement between patient and physician or a method of providing information to the patient and then leaving the patient to make her own decision. ${ }^{57}$

For purposes of this article, we define shared medical decision-making as a process of communication in which the physician and patient use unbiased and complete information on the risks and benefits associated with all viable treatment alternatives and information from the patient on personal factors that might make one treatment alternative more preferable than the others to come to a treatment decision..$^{58}$ While this definition encompasses the traditional disclosure essential for legal informed consent to treatment, it goes beyond the mere recitation of facts, risks and alternatives. Shared decision-making involves a more robust discussion, which engages both the patient and the physician in evaluating the patient's medical goals and lifestyle preferences to come to an informed choice.

As a result, shared decision-making promotes both autonomy and beneficence. While valuable for any medical decision, its methods prove most effective for use with preference sensitive conditions. In this instance, the provider and patient share information to better understand the full scope of the options the patient faces, and to think about the patient's personal values as they relate to the risks and benefits of each option. While the physician and patient jointly participate in the treatment decision, shared decisionmaking prioritizes patient autonomy over beneficence, 
but only enough to tip an otherwise even balance. In instances of disagreement after discussion, the patient's preference should determine the treatment. By protecting patient autonomy and acknowledging the importance of provider opinion and analysis, shared decision-making provides the most effective method of enabling physicians to satisfy their ethical obligations to patients.

While shared decision-making may appear to place a significant burden on physicians, tools exist to facilitate disclosure. A number of organizations have created patient decision aids that provide patients with current scientific evidence on the risks and benefits of treatment options for a specific condition in a format has been slow. The reluctant adoption of SDM has occurred in part because of implementation challenges. However, in the last few years, a variety of academic medical centers around the country have developed shared decision-making programs in different practice areas, demonstrating that implementation is both feasible and worthwhile. ${ }^{64}$ In the next section, we propose a three-phase framework to facilitate integration of shared decision-making into the U.S. health care system.

\section{Integrating Shared Decision-Making}

While the concept of shared decision-making has been present in the medical literature for some time, integrating it into practice has proved challenging. Health services research suggests that physicians rarely engage in shared decision-making in any context. ${ }^{65}$ While many primary care practitioners have expressed interest in shared decision-making, doing so often raises significant administrative challenges and runs counter to current financial and legal incentives. ${ }^{66}$ First, physicians are not reimbursed for time spent discussing treatment options with patients. ${ }^{67}$ Second, fee for service payment systems and a desire to avoid malpractice comprehensible to patients. Decision aids often include patient testimonials on the experience of undergoing different treatment options and patient worksheets to help patients identify advantages and disadvantages specific to them of pursuing particular options. Research demonstrates that after patients have time to review a decision aid, digest the information in it, and think about their personal preferences, their communication with their physician during the treatment decision proves significantly more fruitful. ${ }^{59}$ Studies examining the use of patient decision aids, when used in conjunction with shared decision-making with the physician, have found improvements in patient comprehension and reductions in decisional conflict. ${ }^{60}$ In addition, a number of studies have found an association between increases in patient participation and improved health outcomes. ${ }^{61}$ For instance, two studies found that patients who were more active in their treatment decision had better control of their hypertension than patients who were less involved and expressed fewer opinions about treatment. ${ }^{62}$ Researchers have found similar outcomes in other areas of medical care, including obesity treatment, diabetes management, and breast cancer treatment. ${ }^{63}$

While health services research continues to demonstrate the benefits of shared decision-making for patients, its dissemination into clinical practice claims often provide incentives for physicians to provide services with marginal benefits that the patient might decline if fully informed. Finally, legal informed consent requirements have reduced the medical disclosures in many hospital settings to obtaining a patient's and even less frequently understood. In the absence of clear information and a process that helps elicit their opinions, many patients defer decision-making authority to their physicians. ${ }^{68}$ These incentives have often caused physicians to fall short of their legal and ethical informed consent requirements.

Shared decision-making can remedy these omissions, promote better patient understanding of treatance between provider and patient. In theory, shared decision-making can serve two equally compelling purposes: obtaining legal informed consent and aligning patient goals with the treatment option selected. However, as always the devil is in the details. Many physicians have not received proper training on how to engage patients in the kind of discussion required to fulfill the goals of shared decision-making. While many physicians may adapt quickly to a new method of communication with patients, others will need substantial training on different methods of engaging patients in shared decision-making. In addition, signature on a written form, which is rarely read ment options and strengthen the therapeutic alli- 
changes in financial incentives for physicians may need to be made in order to make shifting their practices toward shared decision-making of an economically rational decision for physicians. Making shared decision-making a mainstay in modern medical practice requires facilitating its use and addressing these challenges through three avenues: (1) practice models; (2) state policy incentives; and (3) federal requirements. The remainder of this section will examine opportunities for implementation at each level.

\section{A. Practice Models}

Modifying heavily entrenched practices can prove extremely difficult, but the availability of a successful, replicable model can assist others to implement change, significantly easing the transition. Shared decision-making is currently used in primary care clinical practice settings at several demonstration sites in the United States. ${ }^{69}$ These programs can serve as models for other hospitals considering integrating shared decision-making into their current practice.

Dartmouth-Hitchcock Medical Center, for example, has had a Center for Shared Decision-Making for the last nine years, which provides the most fully developed model for other practices to follow. While the details vary from condition to condition, the key elements of the Dartmouth Model include: (1) a video decision aid; (2) an online survey and written questionnaire; (3) optional additional resources to help in resolving decisional conflict; (4) shared decision-making communication process; and (5) post-treatment survey. ${ }^{70}$ The following example outlines the decision-making process for a patient recently diagnosed with earlystage invasive breast cancer. ${ }^{71}$

Immediately following her diagnosis at DartmouthHitchcock and prior to the meeting with her surgeon, the Center sends the patient a video decision aid on surgical treatment options for early-stage invasive breast cancer that contains both evidence-based medical information about the options and tools to help the woman clarify her personal values and consider what is most important to her in making her treatment decision. The Center also asks the patient to complete an online questionnaire prior to meeting with the surgeon to discuss treatment options. This questionnaire has two sections. The first asks for general health items including demographic information, and the second inquires about her treatment decision-making process and options. The questionnaire captures the patient's knowledge of the condition and treatment options, the relative priority of her treatment goals, and which treatment choice the patient currently prefers. After viewing the decision aid and answering the questionnaire, the Center also offers the patient the opportu- nity to come in and meet with a decision coach who can help her think through her decision, clarify her personal goals and understand her treatment choices before she meets with the surgeon. The Center then compiles information from the patient's questionnaire and meeting with the decision coach, including that patient's knowledge, values, and overall treatment preferences, into a summary report and provides to the surgeon for use during the surgical consultation.

During the consultation, the surgeon and patient discuss the patient's treatment preferences, the physician's medical opinion, any ambiguities in the treatment options, and then attempt to come to a treatment decision. Analysis of the summary report helps the surgeon identify inconsistencies and misunderstandings in the patient's responses that should be clarified during discussion. For instance, if a patient prioritized conserving her breast in the questionnaire, but then tells her surgeon that she prefers mastectomy, the system will alert the physician to an obvious values/ choice discordance and prompt further discussion. Responses can also prompt the provision of further information. Once the physician and patient agree on a treatment option, the Center directs patients to services appropriate for their selected treatment.

After the initial surgical consultation, women who wish to schedule a consultation with a plastic surgeon to discuss breast reconstruction after mastectomy will receive a video decision aid about treatment choices for reconstruction, while those who wish to schedule a medical oncology consultation will receive a decision aid about chemotherapy and hormone therapy options. Systematic use of these tools prior to meeting with the surgeon allows the clinician to spend appointment time having a more nuanced and directed conversation with each individual patient. Anecdotally, both surgeons and oncologists report spending less time on the basic components of informed consent and a strengthening of therapeutic alliance. $7^{2}$

From both a legal and an ethical perspective, the Dartmouth Model satisfies all elements of a proper informed consent. Through the process of shared decision-making and the use of a decision aid, patients receive current, evidence-based information on the risks and benefits associated with all treatment alternatives. While decision aids can help satisfy the legal requirements of disclosure of risks, benefits and alternatives, they do not go far enough. Only by engaging in the communication required for shared decisionmaking can a physician complete her legal duty of disclosure and satisfy her ethical obligations to respect patient autonomy and promote patient health. Shared decision-making enables patients to align their values and preferences to facilitate treatment selection, and 
in turn allows them to be an engaged and active partner in the chosen treatment process. Following the Dartmouth Model could greatly facilitate adoption and integration of shared decision-making at other academic medical centers, community hospitals, and physician group practices.

\section{B. Policy Incentives}

States can also promote the integration of shared decision-making practice models by altering the current legal and financial incentives in medical care that greatly hinder their adoption. With little to no capital outlay, proactive state legislatures can shift these incentives to facilitate the integration of shared decision-making by passing legislation with two critical components: legal informed consent incentives and selection of an approved certification body.

In the spring of 2007 , the Washington state legislature did exactly that in passing Governor Gregoire's Blue Ribbon Commission Bill on Health Care (ESSB 5930). The bill was the first in the country to acknowledge the benefits associated with shared decision-making and provide legislative support for its integration. First the bill instituted a pilot project to demonstrate the feasibility and financial implications of integrating shared decision-making into primary care for a number of preference sensitive conditions. Group Health of Puget Sound agreed to perform this research, which began in 2008. The findings from this pilot project will prove invaluable to others states in assessing the financial implications of incorporating shared decision-making into primary care. Once completed in Washington, other states may wish to eliminate the pilot project portion of the legislation, which would reduce the time and cost needed for implementation.

Second, the legislature sought to provide legal incentives for physicians to engage in shared decision-making. The bill states that if a competent patient signs a written acknowledgment that he or she engaged in shared decision-making with the use of a certified decision aid, then the signature constitutes "prima facie evidence that the physician received an informed consent to the treatment administered." This presumption can only be disproved by "clear and convincing evidence." The "clear and convincing" evidentiary standard provides more legal protection for physicians who engage in shared decision-making than the "preponderance of the evidence" standard that is currently associated with the use of an informed consent form. Preponderance of the evidence requires patients to demonstrate that it is more probable than not (50.1\%) that the physician did not provide them with all the material information related to the treatment. A clear and convincing evidence standard establishes an even higher burden of proof for patients attempting to claim that they were not adequately informed of the risks or alternatives to their chosen medical treatment. Patients, when signing the form, will be asked to identify the name of the decision aid, and to acknowledge that they had an opportunity to discuss their remaining questions with the physician and that their questions were answered to their satisfaction. As a result, the bill provides physicians significant legal protection for engaging in shared decision-making, while ensuring that patients receive the quantity and quality of information they need and desire to make informed treatment decisions.

Third, the Washington legislature recognized that in order to grant legal protection to physicians for engaging in shared decision-making, the state must establish a method of certifying that the selected decision aids provide patients with current, evidence-based information in an unbiased and easily comprehensible manner. The importance of effective evaluation and certification cannot be overstated. Biased or inaccurate decision aids can alter patient preferences for treatment counteracting the entire goal of shared decision-making. While states may develop their own criteria for approving decision aids, they need not take on this obligation, as an international consortium of researchers, patients, physicians and policy makers from over 14 countries has already risen to the task. The International Patient Decision Aids Collaboration (the Collaboration) recently approved standards for the development and evaluation of decision aids, based on the quality of their information, communication of risk, clarification of key patient values, evidence base, disclosure of support and conflicts of interest, and empirical evidence of its positive impact on patient decision-making. ${ }^{73}$ These standards have been used by the Ottawa Health Research Institute (OHRI) to rate hundreds of patient decision aids. States can adopt either the Collaboration's standards for decision aids and establish a method for certification, or they can adopt only those decision aids that receive a certain rating by OHRI or other similar body in the United States. Once a decision aid receives certification, in order to retain its certification, states should require its producers to update the decision aid with new information every six months or more regularly if a significant breakthrough occurs. Creating webbased decision aids facilitates this type of maintenance and distribution of supplemental information. States may choose to sponsor a state health care decision aid website to ease access and facilitate usage by many citizens.

By passing a simple "win-win-win" bill for patients, physicians, and the state, legislatures can take signifi- 
cant steps toward integrating shared decision-making into medical practice. Legislation like Governor Gregoire's Blue Ribbon Commission Bill on Health Care can improve patient autonomy by increasing comprehension of treatment choices and incentivizing the use of decision aids that assist patients in identifying their personal values and aligning their treatment choices with them. Such a bill also provides additional legal protection to physicians willing to learn to communicate more effectively with patients. Finally, by empowering patients to make more informed and valuesbased treatment choices and incentivizing physicians to engage in shared decision-making, the state may also see a significant reduction in the performance of invasive preference sensitive treatments, resulting in a significant cost savings. ${ }^{74}$ Much of the waste in the health care system stems from costly procedures with either weak supporting evidence, high-risk complications or other significant tradeoffs. ${ }^{75}$ In 2009, Maine and Vermont followed Washington's lead by passing legislation to promote the implementation of shared decision making as an effort to improve the quality of patient decision making and potentially reduce costs..$^{76}$ After the completion of the pilot projects ongoing in Washington, Maine and Vermont, states may be able to better predict the level of expected savings from enacting such a bill.

States considering following such a legislative model should also include a provision in the bill to facilitate physician education. Funding for such Continuing Medical Education (CME) programs could come from anticipated savings, retaining the legislation's revenue neutrality. To more fully integrate these practices, states should also consider requiring all physicians seeking to obtain a medical license or renew a medical license have training in physician-patient communication focused on the process of shared decision-making. As these state programs successfully demonstrate that shared decision-making can be integrated into day to day practice effectively through physician education, can improve patient preference sensitive decision-making, and can reduce overall health care expenditures, shared decision-making should also be integrated on a national level.

\section{Legislative Requirements and Focusing on Medical Necessity}

In order to promote shared decision-making at a national level, Congress should adopt shared decisionmaking principles into federal health care legislation. Senators Ron Wyden and Judd Gregg have recently introduced the "Empowering Medicare Patient Choices Act," which includes a demonstration project to study methods of integrating shared decision-making into care for Medicare beneficiaries. 77 The bill will focus on promoting the use of shared decision making for 11 conditions that account for 40 percent of Medicare spending on inpatient surgery. Implementation will occur in three phases. Phase I is a three-year period that will follow early adopters and provide the Centers for Medicare \& Medicaid Services (CMS) with data. During Phase II - also a three-year period - Medicare will begin to reimburse physicians for engaging in shared decision making through the use of certified decision aids. Finally, in Phase III, the bill will require physicians to use decision aids and engage in shared decision making for certain conditions as a standard of practice..$^{78}$ If passed, the Wyden-Gregg bill will be the first federal legislation to recognize the importance of shared decision-making to the future of health care.

Medical necessity determinations for Medicare and Medicaid provide another ideal opportunity to alter some of the financial incentives that hinder the adoption of shared decision-making and demonstrate its benefit on a national level. ${ }^{79}$ Medical necessity is a major factor in determining whether a specific service is financially covered by CMS. ${ }^{80}$ The Social Security Act prohibits Medicare payments for medical services that are not "reasonable and necessary for the diagnosis and treatment of an illness or injury or to improve the functioning of a malformed body member." ${ }^{\text {11 }}$ Traditionally, insurers accepted physicians' determinations of what constituted reasonable and necessary services. ${ }^{82}$ However, as health care costs have increased, both private and public insurers have begun to review physician recommendations for necessity and reasonableness in making coverage determinations. ${ }^{83} \mathrm{In}$ these reviews, insurers have generally made coverage decisions based on physicians' opinions regarding clinical benefit, without consideration of the individual patient's preferences.

As discussed above, clinical benefit alone does not establish the reasonableness or necessity of all medical interventions. In the $25 \%$ of medical care that is patient preference sensitive, more than one beneficial or medically appropriate treatment option exists. Often the different treatment options vary significantly according to cost and present a wide array of potential risks and benefits to the individual patient. As a result, the determination of whether the particular treatment choice is "reasonable and necessary" must depend on something beyond clinical benefit and physician opinion. Physicians can determine if a patient is clinically appropriate for a specific treatment according to clinical practice guidelines, but in the case of preference sensitive care, clinical appropriateness fails to establish whether a particular treatment is truly medically necessary. Medical necessity should also depend on 
whether the treatment is most likely to satisfy the fully informed patient's goals, values, and preferences. ${ }^{84}$ Medical treatments are not "reasonable and necessary" if once fully informed, the patient would not elect to have the treatment. Failure to include patient goals, values and preferences in medical decisions over and above clinical appropriateness diminishes patient autonomy and results in the provision of unnecessary and unwanted medical treatments. Such overtreatment results in significant unnecessary expense, exposure to iatrogenic errors, and hazardous side effects.

Certainly in cases of preference sensitive care, delegating the decision of whether a treatment constitutes a "medical necessity" to the physician is flawed for several reasons. First, CMS reimburses physicians for the provision of medically necessary services, but not for engaging in a shared decision-making dialogue with the patient to determine the most optimal treat-
Incorporating patient preferences into the definition of medical necessity for preference sensitive care not only improves the likelihood that physicians will satisfy their ethical obligations to patients, it may also reduce overall Medicare expenditures. Teno and colleagues found that while 60 percent of seriously ill Medicare patients preferred palliative care over more aggressive and costly interventions, only 41 percent of those patients felt their care reflected their preference. ${ }^{87}$ As a result, nearly one-quarter of seriously ill Medicare patients received more aggressive and costly care than they wanted. In addition, 35 percent of patients that preferred palliative care reported that the treatment they received was inconsistent with their goals, while another 24 percent were unsure of their treatment goals. ${ }^{88}$ The authors argued that the inconsistency and patient uncertainty was most likely due to poor communication between patient and physician.

While financial and other challenges to integrating shared decision-making into medical practice will remain, incorporating shared decision-making into modern medical practice at all three levels promises significant benefits, not only for patients, but for the health care system as a whole, including cost reductions and improved physician-patient alliance. While the integration of shared decision-making will not occur overnight, we hope that this proposal will contribute to a much needed change in our health care system.

ment choice for that particular patient. Research conducted by Joan M. Teno et al. underscores how poorly physicians predict their patients' preferences. ${ }^{85}$ Therefore, the current system provides financial incentives for physicians to determine that a particular treatment is medically necessary in the abstract, but not to determine if it is necessary for or desired by the particular patient. Second, delegating decision-making in such a way sustains a paternalistic approach that stymies informed patient choice. The consequences of maintaining this system are both costly and unethical. Maintaining the current approach mutes patient voices when they should be heard most clearly, and promotes unwanted or unwarranted utilization of costly and potentially risky treatments. As Jack Wennberg recently noted, if CMS restructured the medical necessity provisions to reward the process of high quality shared decision-making instead of utilization for preference sensitive conditions, Medicare could achieve significant costs savings while ensuring that patients receive the appropriate treatments. ${ }^{86}$
On average, the difference in expenditures between the patients who preferred and received palliative care and the patients who preferred palliative care, but received more aggressive, life-extending treatments amounted to approximately $\$ 40,000$ per patient over one year. ${ }^{89}$ This reduction in expenditures per patient could amount to considerable savings if this model were implemented more widely to affect a significant percentage of the growing Medicare population.

By altering the current beneficence-based standard for medical necessity to include consideration of patient autonomy, more appropriate determinations of medical necessity can be made on a national level. As Mark Pauly argued nearly 30 years ago, necessity is a relative concept. ${ }^{90}$ Only an individual patient can determine whether he or she values the benefits of a particular treatment option more than its risks. Physicians do not have the "conceptual apparatus or information" necessary to make such a treatment determination.91 In cases of preference sensitive care, CMS should require physicians to engage in shared deci- 
sion-making with patients and then conduct a twostep analysis of medical necessity demonstrating both clinical appropriateness and informed patient choice through the shared decision-making process. In short, shared decision-making aligns the legal requirements of informed consent and the ethical obligations owed to the patient in a straightforward coherent fashion and offers the potential for considerable cost savings.

\section{Conclusion}

While physicians, health services researchers, and medical ethicists have advocated the incorporation of shared decision-making into mainstream medical practice for decades, few physicians have successfully integrated the process into their practice. The failure to recognize the provider's ethical imperative to align patient knowledge and patient treatment choices in cases of preference sensitive care is jarring. If a physician performed surgery on the wrong patient, the breach of her ethical and legal duty of care would be patently obvious. Why then do we tolerate a system that prevents identification of the "right" patients due to insufficient information and avoidable ignorance? The truly informed patient may decide to decline breast conservation therapy, spine surgery, or a prostatectomy, thereby making performing surgery on them in the absence of information a breach of a physician's ethical and legal duties. The decision to accept or decline treatment is specific and personal to each patient. The provider's role is to engage the patient in shared decision-making so that the final treatment choice is informed. Nothing less than this disclosure fully complies with the provider's legal and ethical obligation to the patient. This article proposes a three-step process for implementing a nationwide practice of shared decision-making: (1) provide models of successful integration for guidance and assistance; (2) pass legislation on the state level to provide legal incentives to ease the transition; and (3) require all patients with preference sensitive conditions to engage in shared decision-making to select a treatment option as a precursor to a medical necessity determination. While financial and other challenges to integrating shared decision-making into medical practice will remain, incorporating shared decisionmaking into modern medical practice at all three levels promises significant benefits, not only for patients, but for the health care system as a whole, including cost reductions and improved physician-patient alliance. While the integration of shared decision-making will not occur overnight, we hope that this proposal will contribute to a much needed change in our health care system.
Acknowledgement

The authors would like to thank Lois Weithorn and Jack Fowler for their thoughtful comments on previous drafts of this article.

\section{References}

1. J. A. Glover, "The Incidence of Tonsillectomy in School Children," Proceedings of the Royal Society of Med., (May 1938): 1219-1236, reprinted in: International Journal of Epidemiology 37 (2008): 9-19.

2. Id.

3. Id., at 18 .

4. Id.

5. See, e.g., Center for the Evaluative Clinical Sciences, Dartmouth Medical School, "The Quality of Medical Care in the United States: A Report on the Medicare Program," The Dartmouth Atlas of Health Care, 1999, available at <http://www. dartmouthatlas.org/atlases/99Atlas.pdf> (last visited February 3, 2010); J. E. Wennberg and A. Gittelsohn, "Small Area Variations in Health Care Delivery: A Population-Based Health Information System Can Guide Planning and Regulatory Decision-Making," Science 182, 4117 (1973): 1102.

6. Center for the Evaluative Clinical Sciences, Dartmouth Medical School, The Dartmouth Atlas of Health Care, 1998, at 5, available at <http://www.dartmouthatlas.org/atlases/98Atlas. pdf> (last visited February 4, 2010).

7. The origins of the Hippocratic Oath can be traced back to the 4th century B.C. Medical historian Ludwig Edelstein has suggested that it should be viewed as a code of a minority of Pythagorian physicians. The oath was largely ignored in Judeo Christian tradition until the Declaration of Geneva in 1948, when the World Medical Association recast the code in modern terms. The recast oath is explicit that the primary goal of the physician is to promote the health and welfare of the patient. R. M. Veatch, Cross Cultural Perspectives in Medical Ethics (Boston: Jones \& Bartlett Publishers 2000): at 3, 21.

8. M. Sullivan, "The New Subjective Medicine: Taking the Patient's Point of View on Health Care and Health," Social Science and Medicine 56, no. 7 (2003): 1595-604.

9. T. Blank, K. Graves, K. Sepucha, and H. Lewellyn-Thomas, "Understanding Treatment Decision-Making: Contexts, Commonalities, Complexities and Challenges," Annals of Behavioral Medicine 32 no. 2 (2003): 211-217; D. Feldman-Stewart et al., "The Information Required by Patients with Early-Stage Prostate Cancer in Choosing Their Treatment," British Journal of Urology International 86 no. 3 (2001): 218-223.

10. T. E. Quill and H. Brody, "Physician Recommendations and Patient Autonomy: Finding a Balance between Physician Power and Patient Choice," Annals of Internal Medicine 125 no. 9 (1996): 763-769; C. Meyers, "Cruel Choices: Autonomy and Critical Care Decision-Making," Bioethics 18, no. 2 (2004): 104-119; Dr. Lindsey Roenigk, phone consultation March 24, 2009.

11. R. R. Faden and T. L. Beauchamp, A History and Theory of Informed Consent (New York: Oxford University Press, 1986).

12. $I d$

13. T. L. Beauchamp and J. F Childress, Principles of Biomedical Ethics, 5th ed. (New York: Oxford University Press, 2001) at 166.

14. R. Kukla, "Conscientious Autonomy: Displacing Decisions in Health Care,"Hastings Center Report 35, no. 2 (2005): 34-44.

15. L. Snyder and C. Leffler, "Ethics Manual, Fifth Edition," Annals of Internal Medicine 142, no. 7 (2005): 560-82, at 560.

16. See Beauchamp and Childress, supra note 13 , at 176 .

17. E. J. Emanuel and L. L. Emanuel, "Four Models of the Physician-Patient Relationship," JAMA 267, no. 16 (1992): 22212226; T. S. Szasz and M. H. Hollender, "The Basic Models of the Doctor-Doctor Relationship," Archives of Internal Medicine 97, no. 5 (1956): 585-592.

18. J. Savulescu, "Rational, Non-interventional Paternalism: Why Doctors Ought to Make Judgments of What Is Best for Their Patients," Journal of Medical Ethics 21, no. 6 (1995): 327-331. 
19. By definition, paternalism is "the intentional overriding of one person's known preferences or actions by another person, where the person who overrides justifies the action by the goal of benefiting or avoiding harm to the person whose preferences or actions are overridden." See Beauchamp and Childress, supra note 13 , at 178 .

20. See Savulescu, supra note 18.

21. D. E. Collins, C. P. Moore, K. F. Clay et al., "Can Women with Early-Stage Breast Cancer Make an Informed Decision for Mastectomy?" Journal of Clinical Oncology 27, no. 4 (2009): 519-525; see Blank et al., supra note 9; D. Feldman-Stewart et al., "Practical Issues in Shared Decision-Making," Health Expectations 3, no. 1 (2000): 46-54; J. M. Teno et al., "Preferences for Cardiopulmonary Resuscitation: Physician-Patient Agreement and Hospital Resources Use," Journal of General Internal Medicine 10, no. 4 (1995): 179-186.

22. Canterbury v. Spence, 464 F.2d 772 (D.C. Cir. 1972).

23. American Medical Association, §E-8.08; American Medical Association, Informed Consent: Code of Medical Ethics, Chicago, 2006 , at 227 .

24. C. E. Schneider, The Practice of Autonomy: Patients, Doctors and Medical Decisions (New York: Oxford University Press, 1998); see Savulescu, supra note 18.

25. Lane v. Candura, 6 Mass. App. Ct. 377 (1978).

26. T. A. Brennan et al., "Medical Professionalism in the New Millennium: A Physician Charter," Annals of Internal Medicine 136, no. 3 (2002): 243-246, at 244. Emphasis added.

27. Patient-Centered Primary Care Collaborative, "Joint Principles of the Patient Centered Medical Home," February 2007, available at <http://www.pcpcc.net/content/joint-principlespatient-centered-medical-home> (last visited February 4, 2010).

28. National Priorities Partnership, Patient and Family Engagement, 2008, available at <http://www.nationalprioritiespartnership.org/PriorityDetails.aspx?id=596> (last visited February 4,2010 ).

29. S. H. Woolf, E. C. Y. Chan, R. Harris, S. L. Sheridan, C. H. Braddock, and R. M. Kaplan et al., "Promoting Informed Choice: Transforming Health Care to Dispense Knowledge for Decision-Making," Annals of Internal Medicine 143, no. 4. (2005): 293-300; J. H. Hibbard, "Moving Toward a More Patient-Centered Health Care Delivery System," Health Affairs Suppl. Web Exclusive October 7, 2004: 133-135.

30. "Sicker patients" included patients who reported being in fair or poor health, having had a serious illness, being hospitalized, or having had a major surgery in the past two years.

31. Commonwealth Fund, First Report and Recommendations of the Commonwealth Fund's International Working Group on Quality Indicators: A Report to Health Ministers of Australia, Canada, New Zealand, the United Kingdom, and the United States, 2004.

32. Id.

33. For further discussion of these challenges, see infra Section II.

34. The nine domains included: clinical skill, provision of information, interpersonal skill, office support staff, patient involvement, non-financial access, coordination of care, finances, and office environment. C. E. Laine et al., "Important Elements of Outpatient Care: A Comparison of Patients; and Physicians' Opinions," Annals of Internal Medicine 125, no. 8 (1996): 640645.

35. C. H. Braddock, S. D. Fihn, W. Levinson, A. R. Jonsen, and R. A. Pearlman, "How Doctors and Patients Discuss Routine Clinical Decisions: Informed Decision-Making in the Outpatient Setting," Journal of General Internal Medicine 12, no. 6 (1997): 339-345.

36. D. R. Calkins et al., "Patient-Physician Communication at Hospital Discharge and Patients' Understanding of the Postdischarge Treatment Plan," Archives of Internal Medicine 157, no. 9 (1997): 1026-1030.

37. S. M. Scheitel, B. J. Boland, P. C. Wollan, and M. D. Silverstein, "Patient-Physician Agreement about Medical Diagnoses and Cardiovascular Risk Factors in the Ambulatory General Medicine Examination," Mayo Clinical Proceedings 71, no.12 (1996): 1131-1137.

38. A. M. O'Connor, C. L. Bennett, D. Stacey, and M. Barry et al., "Decision Aids for People Facing Health Treatment or Screening Decisions," Cochrane Database of Systematic Revieres 2 (2003), updated Cochrane Database of Systematic Reviews 3 (2009), available at <http://decisionaid.ohri.ca/cochsystem. html> (last visited February 4, 2010); J. E. Wennberg, A. M. O'Connor, E. D. Collins, and J. N. Weinstein, "Extending the P4P Agenda Part 1: How Can Medicare Improve Patient Decision-Making and Reduce Unnecessary Costs?" Health Affairs 26 , no. 6 (2007): 1564-1574.

39. See Box 1 for examples of Preference Sensitive medical conditions.

40. G. A. Hawker et al., "Determining the Need of Hip and Knee Arthroplasty: The Role of Clinical Severity and Patients' Preference," Medical Care 39, no. 3 (2001): 206-216.

41. See Wennberg, supra note 38.

42. See Meyers, supra note 11; Schneider, supra note 25; H. Madder, "Existential Autonomy: Why Patients Should Make Their Own Choices," Journal of Medical Ethics 23, no. 4 (1997): 221225; Quill and Brody, supra note 11; Savulescu, supra note 18.

43. See Quill and Brody, supra note 10.

44. See Schneider, supra note 24.

45. C. E. Laine and F. Davidoff, "Patient-Centered Medicine: A Professional Evolution," JAMA 275, no. 2 (1996): 152-156.

46. See Savulescu, supra note 18.

47. Dr. Lindsey Roenigk, phone conversation with authors March 24, 2009; see supra note 43.

48. T. van Kleffens, B. van Baarsen, and E. van Leeuwen, “The Medical Practice of Patient Autonomy and Cancer Treatment Refusals: A Patients' and Physicians' Perspective," Social Science and Medicine 58, no. 11 (2004): 2325-2336.

49. See Collins, supra note 21.

50. Id.

51. Id.

52. W. Levinson et al., "Not All Patients Want to Participate in Decision-Making: A National Study of Public Preferences," Journal of General Internal Medicine 20, no. 6 (2005): 531535; D. J. Mazur and D. H. Hickam, 'Patients' Preferences for Risk Disclosure and Role in Decision-Making for Invasive Medical Procedures," Journal of General Internal Medicine 12, no. 6 (1997): 114-117.

53. D. J. Mazur et al., "The Role of Doctor's Opinion in Shared Decision-Making: What Does Shared Decision-Making Really Mean When Considering Invasive Medical Procedures?" Health Expectations 8, no. 2 (2005): 97-102; J. L. Bernat and L. M. Peterson, "Patient-Centered Informed Consent in Surgical Practice," Archives of Surgery 141, no. 1 (2006): 86-92.

54. J. S. King and B. Moulton, "Rethinking Informed Consent: The Case for Shared Medical Decision-Making," American Journal of Law and Medicine 32, no. 4 (2006): 429-501; Beauchamp and Childress, supra note 13.

55. See Beauchamp and Childress, supra note 12.

56. G. Moumjid et al., "Shared Decision-Making in the Medical Encounter: Are We Talking about the Same Thing," Medical Decision-Making 27, no. 5 (2007): 539-546.

57. Id.

58. See King and Moulton, supra note 54; R. M. Kaplan, "Shared Medical Decision-Making: A New Tool for Preventative Medicine," American Journal of Preventative Medicine 26, no. 1 (2003): 81-83.

59. A. M. O'Connor et al., "Decision Aids for Patients Facing Health Treatment or Screening Decisions: Systemic Review," British Medical Joumal 319(1999): 731-734

60. See Collins, supra note 21, A. M. O'Connor et al., "Do Patient Decision Aids Meet Effectiveness Criteria of the International Patient Decision Aid Standards Collaboration? A Systematic Review and Meta-analysis," Medical Decision-Making 27, no. 5 (2007): 554-574. 
61. E. Guadagnoli and P. Ward, "Patient Participation in DecisionMaking" Social Science Medicine 47 no. 3 (1998): 329-339; S. H. Kaplan et al., "Assessing the Effects of Physician-Patient Interactions on the Outcomes of Chronic Disease," Medical Care 27, no. 3 (1989): S110-S127; P. Mendonca and S. Brehm, "Effects of Choice on Behavioral Treatment of Overweight Children," Journal of Social Clinical Psychology 1, no. 4 (1983): 343-358; B. A. Schulman, "Active Patient Orientation and Outcomes in Hypertensive Treatment," Medical Care 17, no. 3 (1979): 267-280.

62. See Kaplan, supra note 61; Schulman, supra note 61.

63. Id. (Kaplan); Mendonca and Brehm, supra note 61.

64. A number of primary care practices have successfully adopted shared decision-making and the use of decision aids, including the University of North Carolina (UNC), Chapel Hill, NC; White River Junction VA, White River Junction, VT; Massachusetts General Hospital (MGH), Boston, MA; University of California Los Angeles (UCLA), Los Angeles, CA; University of California San Diego (UCSD), San Diego, CA; Maine Health - Portland, ME; Mercy Medical Center, Des Moines, IA; Stillwater Hospital, Stillwater, MN; Oregon Health Science, Portland, OR; Palo Alto Medical Center, Palo Alto, CA; and Dartmouth Hitchcock Medical Center (DHMC), Hanover, NH. In addition, specialty practices at the University of California, San Francisco (UCSF) and DHMC have also adopted shared decision-making and the use of decision aids.

65. See Braddock, supra note 35; R. M. Epstein, B. S. Alper, and T. E. Quill, "Communicating Evidence for Participatory DecisionMaking," JAMA 291, no.19 (2004): 2359-2365.

66. S. H. Woolf, "The Logic and Limits of Shared Decision-Making," Journal of Urology 166, no. 1 (2001): 244-245.

67. J. E. Wennberg et al., "Improving Quality and Curbing Health Care Spending: Opportunities for the Congress and the Obama Administration," Dartmouth Atlas White Paper, December 2008.

68. $I d$.

69. See supra note 64 .

70. Conversation and email communication with authors and $\mathrm{K}$. Clay and S. Berg regarding the Dartmouth Hitchcock Center for Shared Decision-Making, December 12, 2008.

71. See Collins, supra note 21; Clay and Berg, supra note 70.

72. Id. (Clay and Berg).

73. See Wennberg, supra note 38.

74. Id.

75. See Woolf, supra note 29.
76. "An Act Relating to Containing Health Care Costs," Senate Bill 129, S.J. 50P, signed into law May 28, 2009, avaitable at <www.leg.state.vt.us/database/status/summary. $\mathrm{cfm}$ ? Bill $=$ S.0129\&Session $=2010>$ (last visited February 4, 2010); "Resolve, To Study Implementation of Shared Decision Making To Improve Quality of Care and Reduce Unnecessary Use of Medical Services," 124th Maine Legislature, SP 493, LD \# 1398, signed into law June 9, 2009, available at <www.mainelegislature.org/legis/bills/display_ ps.asp?LD=1358\&snum=124> (last visited February 4, 2010).

77. Senator Wyden, Wyden, Gregg, Blumenauer Put Patients in the Driver's Seat, Press Release, <http://wyden.senate.gov/ newsroom/record.cfm?id $=313384 \&>$ (last visited February 4 , 2010).

78. <http://www.thomas.gov/cgi-bin/query/F?c111:1:./ temp/ c111VQGDjp:e1180:> (last visited February 4, 2010).

79. See Wennberg, supra note 67.

80. Not all covered services are medically necessary for each patient and not all medically necessary services are covered. P. A. Glassman, K. E. Model, J. P. Kahan, P. D. Jacobsen, and J. W. Peabody, "The Role of Medical Necessity and Cost-Effectiveness in Making Medical-Decisions," Annals of Internal Medicine 126, no. 2 (1997): 152-156.

81. 42 USC $\$ 1395 y(a)(1)(A)(2009)$

82. S. Rosenbaum and D. M. Frankford, "Who Should Determine When Health Care Is Medically Necessary?" New England Journal of Medicine 340, no. 3 (1999): 229-232.

83. Id.; L. A. Berghold, "Medical Necessity: Do We Need It?" Health Affairs 14, no. 4 (1995): 180-190.

84. See Wennberg, supra note 38.

85. See Teno, supra note 21.

86. See Wennberg, supra note 38.

87. J. M. Teno, E. S. Fisher, M. B. Hamel, K. Coppola, and N. V. Dawson, "Medical Care Inconsistent with Patients' Treatment Goals: Association with 1-Year Medicare Resource Use and Survival," Journal of the American Geriatrics Society 50, (2002): 496-500.

88. Id.

89. Id.

90. M. V. Pauly, "What Is Unnecessary Surgery?" Milbank Memorial Fund Quarterly - Health $\varsubsetneqq$ Society 57, no. 1 (1979): 95-117.

91. L. L. Leape, "Unnecessary Surgery," Health Research Services 24, no. 3 (1989): 351-407. 